\title{
Physiotherapy Of Pain In Patients With Cancer Receiving Palliative Care
}

\section{Palyatif Bakım Alan Kanser Hastalarında Ağrı Fizyoterapisi}

\author{
Mesut Ergan', Zeliha Başkurt ${ }^{1}$ \\ Süleyman Demirel Üniversitesi, Sağlık Bilimleri Fakültesi, Fizyoterapi Ve Rehabilitasyon Ana Bilim Dalı, \\ Isparta
}

Dergiye Ulaşma Tarihi: 15.04.2019 Dergiye Kabul Tarihi: 14.05.2019 Doi: 10.5505/aot.2019.80557

\section{ÖZET}

Ülkemizde, sağlık sistemine yakın zamanda giren palyatif bakım hizmetleri giderek yaygınlaşmaktadır. Ağrı, palyatif bakım ünitelerinde hastaların yaşam kalitesini etkileyen en önemli semptomdur. Kanserle ilişkili ağrı, sinir hasarı veya duyu tipi mekanizmasına dayanarak kolayca kategorize edilebilir, ancak çoğu ağrı aslında karışıktır. $\mathrm{Bu}$ sebeple hasta ve ağrı nedeniyle ilgili güvenilir bilgiler hemen sağlanmalı ve ağrıyı değerlendirmek için kabul görmüş ağrı ölçekleri kullanılmalıdır. Palyatif onkolojide çeşitli farmakolojik ve invaziv girişimlerin yanı sıra ağrı tedavisinde etkinliği gösterilmiş fizyoterapi uygulamaları da kullanılmalıdır. Ağrı tedavisi çok modlu bir yaklaşımı içerir. Fizyoterapi; terapötik egzersizler, manuel tedavi teknikleri, gevşeme, postüral re-eğitim, pozisyonlama, mobilite, TENS, sıcak veya soğuk uygulama ve masaj gibi birçok yöntemi içerebilir. Ayrıca, ağrı tedavisine aktif katılım için, hastaya ve ailesine mutlaka eğitim verilmelidir. Bu şekilde palyatif onkolojide ağrı tedavisi daha başarılı bir şekilde gerçekleştirilebilir. Bu derlemenin amacı, palyatif onkolojide ağrı ve fizyoterapisi ile ilgili bilgileri ele almaktır.

Anahtar Kelimeler: Palyatif bakım, kanser, ağrı, fizyoterapi

\begin{abstract}
The palliative care services that have recently got into the health system are becoming more common in our country. Pain is the most important symptom that affects the quality of life of the patients in palliative care units. Cancer-related pain can be easily categorized based on nerve damage or sensory-type mechanism, but most pain is actually complicated. Therefore, reliable information on the patient and the cause of pain should be provided immediately, and accepted pain scales should be used to assess pain. Except from the various pharmacological and invasive procedures in palliative oncology, physiotherapy applications that have been shown to be effective in the treatment of pain should also be used. Pain therapy involves a multimodal approach. Physiotherapy can include many methods such as therapeutic exercises, manual therapy techniques, relaxation, postural re-training, positioning, mobility, TENS, hot or cold application and massage. In addition, for active participation in pain therapy, the patient and his / her family should be educated. Pain treatment in palliative oncology can be performed more successfully with these applications. The aim of this review is to determine the knowledge about pain and physiotherapy in palliative oncology.
\end{abstract}

Keywords: Palliative care, cancer, pain, physiotherapy

\section{GíRiş}

Palyatif bakım, çeşitli kronik hastalıklar nedeniyle iyileşemeyen veya yaşamının son zamanlarında desteğe ihtiyaç duyan hastalara yardım etmeyi amaçlamaktadır ve önemi son zamanlarda giderek artmaktadır (1). Dünya Sağlık Örgütü'ne (DSÖ) göre palyatif bakım; yaşamı tehdit eden hastalıkla karşı karşıya kalan genç ve yaşlı hastaların ve ailelerinin yaşam kalitesini artıran bir yaklaşımdır. Böylece, hastaların ağrı ve diğer fiziksel, psikososyal ve ruhsal problemlerinin erken teşhisi, değerlendirilmesi ve tedavisi ile acı çekmenin önlenmesi veya azaltılması sağlanır. Her yıl 40 milyon insanın palyatif bakıma ihtiyac1 bulunmaktadır, ancak palyatif bakım ihtiyacı olan insanların sadece \% 14'ü şu anda bu hizmetten faydalanabilmektedir (2). 
Hem kanser insidansının artması hem de çeşitli tedavi seçeneklerinin denenmesi ile kanser tanılı bireylerin yaşam sürelerinin uzaması, kanserli hastaların palyatif bakıma olan ihtiyacını artırmıştır.

Ağrı nörofizyolojisi, değerlendirmesi ve tedavisindeki ilerlemelere rağmen, kanser hastalarında, özellikle metastazı bulunan hastalarda en çok bildirilen semptomlardan biridir $(4,5)$. Bu problem, ağr1 ve kanser prevalansının evrensel olarak yükselmesi nedeniyle artmaya devam etmektedir. DSÖ, kanser ağrısının 5,5 milyon insanı etkilediğini tahmin etmektedir (5). İlerlemiş kanserde ağrı prevalans1 yaklaş1k \% 70'tir, ancak bu oranlar hem kanser tipi hem de hastalık evresine göre değişmektedir (4).

DSÖ'nün analjezik merdiven yöntemi kanser ağrısı olan hastalarda en çok kabul gören ve yaygın olarak kullanılan ağrı yönetimi stratejisidir. Kanser ağrılı hastalarda opioidler, halen en çok tercih edilen ilaç terapisidir (6). Ağrı yönetimi ve palyatif bakım alanlarındaki büyük ilerlemelere rağmen kanserle ilişkili ağrının tedavisi hala yetersizdir (7). Toplum temelli bir çalışmada, ağrı tedavisinin kanser hastalarının \% 42'sinde yetersiz olduğunu göstermiştir (8). Analjezikler ile birlikte kullanılan farmakolojik olmayan yöntemler, kanserli hastanın fonksiyonelliğini korumayı ya da geliştirmeyi ve ağrılı durumlar üzerindeki psikolojik kontrol duygusunu yeniden sağlamayı hedeflemektedir. Palyatif bakımda ağrı tedavisi için fizyoterapistler tarafindan uygulanan çeşitli terapötik yöntemler, farmakolojik olmayan müdahalelerin bir bölümünü oluşturmaktadır (9).

Ülkemizde sağlık sistemine yakın zamanda giren palyatif bakım hizmetleri giderek yaygınlaşmaktadır. Palyatif bakım ünitelerinde, hastaların yaşam kalitesini en çok etkileyen semptom olan ağrının kontrolü oldukça önemlidir. Terminal dönem kanser hastalarında ağrının tedavisinde, farmakolojik ve cerrahi seçeneklerin yanı sıra etkinliği kanıtlanmış fizyoterapi gibi nonfarmakolojik tedaviler de kullanılmalıdır. Eğitimler ile hastanın ve ailesinin tedaviye aktif katılımı muhakkak sağlamalıdır. Bu şekilde palyatif bakımda ağrı, daha başarılı şekilde tedavi edilebilir (10).

KANSER AĞRISININ MEKANIZMASI
Kanser ağrisında; kanser hücreleri, periferik ve merkezi sinir sistemi ve bağışıklık sistemi arasında karmaşı bir etkileşim bulunmaktadır. Kanser hücreleri ve lokal bağışıklık hücreleri, nosiseptörleri aktive eden ve hassaslaştıran aracı maddeler üretir ve salgılar (11). Ağrı algısının nosiseptörlerle doğrudan ilişkisi olmayan faktörlere (anksiyete, depresyon, dikkat dağınıklığı) bağlı olarak değişebileceğinin gözlemlenmesi, transdüksiyonu ve yanıtı modüle eden ek mekanizmaların varlığına işaret etmektedir. Kanser ağrısı, sinir hasarı veya duyu tipi mekanizmasına dayanarak kolayca kategorize edilebilir, ancak çoğu ağrı aslında karışıktır. (Tablo 1) (12).

Tablo 1. Kanserde Sık Karşıslaşılan Ağrı Tipleri

\begin{tabular}{|c|c|c|}
\hline Ağrı Tipi & Neden & Karakteristik \\
\hline $\begin{array}{l}\text { Nosiseptif } \\
\text { ağrı }\end{array}$ & Sinirler üzerine bask1 & $\begin{array}{ll}\text { Derin, s1kıc1, } & \text { ac1 } \\
\text { şeklinde, sürekli } & \text { ve } \\
\text { zamanla kötüleșen } & \end{array}$ \\
\hline $\begin{array}{l}\text { Viseral } \\
\text { ağrı }\end{array}$ & Organın gerilmesi & $\begin{array}{l}\text { Kramp, şişkinlik } \\
\text { ağrıs1, aralıklı şekilde }\end{array}$ \\
\hline & $\begin{array}{l}\text { Kanserden/tedaviden } \\
\text { ya da her ikisinden } \\
\text { sinirlere direkt hasar }\end{array}$ & $\begin{array}{l}\text { Lokal ağrı, sızlama, } \\
\text { yanma, bıçak saplanır } \\
\text { tarzda ağrı, allodini, } \\
\text { hiperaljezi }\end{array}$ \\
\hline $\begin{array}{l}\text { Noropatık } \\
\text { ağrı }\end{array}$ & $\begin{array}{l}\text { Kemoterapi kaynaklı } \\
\text { nöropatik ağrı, } \\
\text { reseptör hasar, sinir } \\
\text { lif yoğunluğu kaybı, } \\
\text { uzun sinirlere } \\
\text { doğrudan hasar }\end{array}$ & $\begin{array}{l}\text { Uyuşma, } \\
\text { karıncalanma ve ağrı; } \\
\text { uzun sinirler en çok } \\
\text { etkilenir, Çorap - } \\
\text { eldiven nöropatisi }\end{array}$ \\
\hline $\begin{array}{l}\text { Bir olay } \\
\text { veya } \\
\text { harekete } \\
\text { bağlı ağrı }\end{array}$ & $\begin{array}{l}\text { Patolojik kırıklar, } \\
\text { kansere bağlı kemik } \\
\text { hasarı, kanserden } \\
\text { sonra kalan hasar }\end{array}$ & $\begin{array}{l}\text { Dinlenmede minimal } \\
\text { ağrı, hareketle birlikte } \\
\text { ağrı artar, kontrol } \\
\text { etmek çok zordur. }\end{array}$ \\
\hline \multicolumn{3}{|c|}{$\begin{array}{l}\text { Smith TJ, Saiki CB. Cancer Pain Management. Mayo Clin } \\
\text { Proc. 2015;90(10):1428-1439 }\end{array}$} \\
\hline
\end{tabular}

\section{KANSER AĞRISININ DEĞERLENDİRILMESİ}

Ağr1 subjektiftir ve sadece fiziksel bir deneyim değildir. Ağrı ifadesi; rahatsızlık, fonksiyonel gerileme, bağımlılık, ailesel problemler ve yaşam kalitesini tehdit eden maddi yüklerden etkilenir (13). Dame Cicely Saunders, terminal dönem hastalarında ağrının fiziksel, emosyonel, sosyal ve manevi bileşenlerini tanımlamak için toplam ağrı terimini kullanmıştır. $\mathrm{Bu}$ dört boyut, tek başlarına veya kombinasyon halinde hastaların ağrı algılayışını etkiler ve bu sebeple tüm 
terminal dönem hastalarında muhakkak araştırılmalıdır (14).

Palyatif bakımda ağrının düzenli aralıklarla değerlendirilmesi gerekmektedir. Ağrı subjektif bir semptom olduğu için hastaları her yönüyle tanıma, hikayenin doğru alınması, hastayı sürekli gözlemleme ve değerlendirmede uygun yöntemlerin kullanılması gerekmektedir (3). Ayrıca, ağrının özelliklerinin, çeşitli problem kaynaklarının (fiziksel, psikolojik, manevi ve sosyal), etiyoloji ve muhtemel mekanizmanın, yaşam kalitesinin, bireysel hedeflerin, risk faktörleri ve engellerin belirlenmesi önem arz etmektedir (15). Hastaya ve ağrı nedenine ilişkin güvenilir bilgiler hemen sağlanmalı ve herkes tarafından kabul görmüş ve farklı yorumlara sebep olmayan ağrı ölçekleri kullanılmalıdır (3).

Ăğı Karakteristiği ve Yoğunluğunun Değerlendirilmesi

Hastalara ağrının şiddeti, niteliği, yeri, zamansal ilişkisi, günlük değişimi, süresi gibi özellikleri ve ağrıyı artırıcı/hafifletici faktörler muhakkak sorulmalıdır. Ağrılı bölgeler hastanın üzerinden ya da vücut diyagramı kullanılarak lokalize edilebilir. Hastaların ağrılarının niteliği ile ilgili açıklayıcı sözleri nedene ilişkin ipuçları sağlayabilir.

Sayısal Derecelendirme Ölçeği (The Numeric Pain Rating Scale (NRS)), Görsel Analog Skala (VAS) ve Resim Ölçeği (The Picture Scale) ağr1 şiddetini belirlemek için kullanılan geçerli ölçeklerdir. Tutarlılık için tedavi boyunca hasta aynı ölçekle değerlendirilmelidir. Her ölçeğin hastanın yaşına, iletişim becerilerine ve kognitif durumuna göre avantaj ve sinırlılıkları vardır. NRS, Edmonton Semptom Tanılama Ölçeği gibi çok parçalı değerlendirme ölçeklerine de dahil edilmiştir. Sözel Derecelendirme Ölçeği (The Verbal Rating Scale), hastaların "yok", "hafif", "orta" veya "şiddetli" gibi kelimeleri kullanarak ağrı şiddetini derecelendirmelerini gerektirir. Wong-Baker FACES Ağr1 Değerlendirme Ölçeği, mutludan mutsuza doğru çeşitli yüz ifadelerini içeren bir dizi çizimden oluşur (13).

Ağrı şiddeti, ağrının hastaya ve tedavi sürecine olan etkilerini belirleyen dominant faktördür. 4-5 veya daha yüksek ağrı şiddeti skorlarının tedaviyi zorlaştırdığı ve yaşam kalitesini bozduğu gösterilmiştir (16). Ancak bazen hastalar hafif ağrıyı şiddetli, şiddetli ağrıyı hafif şeklinde tanımlayabilir. $\mathrm{Bu}$ durumlarda ağrı şiddetini ve fonksiyonelliğe etkisini doğrulayan Memorial Ă̆r Değerlendirme Kartı (Memorial Pain Assessment Card) ve Kısa Ağrı Envateri (Brief Pain Inventory) kullanılabilir $(13,17)$.

\section{Kognitif Bozuklukları Olan Hastalarda Ağrı Değerlendirmesi}

İleri düzey kanserli hastalarda deliryum $\% 28$ ile $\% 40$ oranları arasında görülmektedir $(18,19)$. Deliryum; farkındalığın azalması, algısal bozukluklar, akut başlangıç ve dalgalı seyri gibi diğer özelliklerin yanı sıra, bilişsel bozulma ve özellikle düzensiz dikkatle teşhis edilir. Hiçbir objektif bilişsel test yapılmadığında deliryum gözden kaçabilir ve yanlış değerlendirme ve tedaviye yol açabilir. Mini Mental Durum Değerlendirme Testi, kognitif bozukluklar ve hasta öz-bildirim puanlarının güvenilirliğine ilişkin yararlı bilgiler sağlar (13). Ayrıca, deliryum şiddetini ölçmek için Memorial Delirium-Değerlendirme Ölçeği'de kullanılabilir (20).

Hafif ile orta dereceli kognitif bozukluğu olan hastalar genellikle ağrı ölçeklerine kendileri cevap verebilirler. Ancak, şiddetli bozukluğu olan hastalarda, sadece birkaç soru sormak, davranışları gözlemlemek ve aileden bilgi toplamak mümkün olabilir. Bakıcılar ağrıya işaret edebilecek davranışları bildirmek için eğitilmelidir (13). Yüz, Bacak Hareketliliği, Aktivite, Ağlama, Teselli Edilirlik Skalası (FLACC) demanslı hastalarda davranışsal ağrı değerlendirme araçları olarak kullanılmaktadır (21).

\section{KANSER AĞRISINDA FİZYOTERAPİ VE REHABILITTASYON UYGULAMALARI}

Fizyoterapi kanser ağrılı hastaların tedavisinde önemli bir rol oynamaktadır ve bu hastalarla "kanser yolculuğunda" çeşitli aşamalarda karşılaşılabilmektedir. Kanserde rehabilitasyon gün geçtikçe artan bir şekilde ilgi görmektedir ve günümüzde bakımın sağlanmasında önemli bir bileşen olarak kabul edilmektedir.

Tedavinin temel amac1, mevcut olan kanıtlara dayalı tedavileri kullanarak ağrıyı azaltmak ve yaşam kalitesini ve fonksiyonunu iyileştirmektir. Tedavi hasta merkezli olmalıdır. Belirlenen hedeflere ulaşmak için tedaviye aile ve bakıcılarda dahil edilmelidir. Erken tedavi sadece palyatif bakım hastalarında değil aynı 
zamanda kronikleşmeyi ve tahmin edilen problemleri önlemek için diğer hastalarda da büyük önem arz etmektedir (22).

Ağrı tedavisi çok modlu bir yaklaşımı içerir. Fizyoterapi; terapötik egzersizler, manuel tedavi teknikleri, gevşeme, postüral reeğitim, pozisyonlama, mobilite, TENS, sicak veya soğuk uygulama ve masaj gibi yöntemleri içerebilir (23).

\section{Sicak ve Soğuk Uygulama}

Sıcak ve soğuğun çeşitli fizyolojik süreçler üzerinde belirgin etkileri vardır. $\mathrm{Bu}$ nedenle ana kullanımları yararlarının desteklendiği kas iskelet sistemi üzerine odaklanmış ağrn kontrolü için olmuştur (24). Metabolik ve enzimatik süreçler sicaklığa oldukça duyarlıdır. Sadece birkaç ${ }^{\circ} \mathrm{C}$ değişiklik sinir iletimini, kan akışını ve kollajen uzayabilirliğini değiştirebilir (25). Soğuk uygulama, periferik ve merkezi sinir sistemi mekanizması aracılığıyla ağrı algılamasını azaltmaktadır. Lokal olarak vazokonstrüksiyon sağlayarak nosiseptörlerin duyarlılığını azaltır (26). Isıtma ajanları farklı olmasına rağmen çoğunluğu analjezi veya hiperemiyi indükleyerek veya kas tonusunu azaltarak etkilerini gösterirler. Sicak ve soğuğun etkililiği üzerine yapılan araştırmalar incelenen koşulların çeşitliliği ve kullanılan tekniklerin özellikleri ile sınırlanmıştır. Ancak kanıtlar, inanıldığg gibi sıcak ve soğuğun tek başlarına da faydalı olduğunu, iyi planlanmış bir egzersiz ve mobilizasyon programı ile birleştirildiğinde faydalarının daha büyük olduğunu göstermektedir (27).

\section{TENS}

TENS öncelikle A-beta sinir liflerinin stimülasyonu yoluyla ağrı algısını değiştirir ve bu da A-delta ve C-liflerinin aracıllk ettiği bir nosiseptif uyaranın iletimini engelleyebilir. Aalfa liflerinin uyarımı da (motor stimülasyonu veya akupunktur benzeri TENS) nosiseptif yolakların benzer inhibisyonunu sağlayabilir, ancak daha yoğun stimülasyon gerektiği ve tolerasyonu zayıf olduğu için genellikle aktif kanser hastaları için önerilmemektedir. TENS'in kanser popülasyonunda ki etkisi tartışmalıdır. Tümör büyümesi anjiyogenez ve kan akışına büyük ölçüde bağımlıdır ve kan akışının artması tümörlere oksijen ve besin maddeleri sağlar. Son çalışmalar, TENS uygulanan bölgede yüksek kan akımının sebebinin kas aktivitesinin artması olduğunu ve motor eşiğin altındaki yüksek frekans veya düşük frekanslı TENS'in kan akışı üzerinde klinik olarak anlamlı bir etkiye sahip olmadığını göstermektedir. Ancak, yüksek frekanslı TENS ( $80 \mathrm{~Hz}$ üzeri) kan akışı üzerinde minimal etkiye sahip olduğu için daha güvenlidir (28).

\section{Düşük Seviyeli Lazer}

Düşük seviyeli lazer (DSL)'nin nontermal etkileri; adenosin trifosfat üretiminin uyarılması, ribonükleik asit ve kollajen üretiminin artırılması, inflamatuar sitokinlerin modülasyonu, bakteriyel üremenin inhibisyonu, vazodilatasyon ve endotel rejenerasyonun artırımı, fibroblast aktivitesinin uyarılması, sinir iletim hızının değişimi ve nöral rejenerasyonun artırılması şeklindedir. Düşük seviyeli lazer tedavisinin, mukozitin şiddetini azalttığı yönünde zayıf kanıtlar vardır (29). Göğüs kanseri ilişkili lenfödemli hastalarda yapılan bir sistematik incelemeden orta düzey kanıtlara ulaşılmış ve DSL tedavisinin kol hacminde ve ağrıda klinik olarak anlamlı azalma sağladığı belirtilmiştir (30).

\section{Ultrason}

Terapötik olarak ultrason, ağrny1 azaltmak için fizyoterapistler tarafindan sıklıkla kullanılmaktadır ve şu anda kanser tedavisinde kullanımı için araştırmalar devam etmektedir. Teorik olarak terapötik ultrason, doku sıcaklığının artması ve hücre geçirgenliği ve hücre büyümesi gibi fizyolojik değişiklikleri indükleyerek etki gösterir. $\mathrm{Bu}$ etkiler ile yumuşak doku iyileşmesini ve kas relaksasyonunu sağladığı düşünülmektedir. Kas iskelet sistemi problemleri palyatif bakım popülasyonunda önemli bir ağrı nedenidir. Ultrason, terminal dönem hastaların yaşam kalitesinin artırılmasında rol oynayabilir ancak, ağrının giderilmesinde ultrasonu destekleyen çok az kanıt vardır (31).

\section{Masaj Terapisi}

Kanser hastalarında semptomların giderilmesi için, eller ya da mekanik cihazların yardımıyla yapılan masaj terapisinin kullanımı giderek artmaktadır (32). Birçok kanser hastası masajı sadece fiziksel rahatlama ve ağrıdan kurtulmak için değil aynı zamanda duygusal problemler, fonksiyonel yetenek ve genel yaşam kalitesine yardımcı olması içinde tercih etmektedir (33).

Masaj, dokularda gevşeme sağlar, dolaşımı arttırır ve kas spazmını azaltır. Bazı masaj yöntemleri ise serotonin ve opioidlerin 
serbestleşmesini aktive ederek ağrıyı inhibe etmektedir (34). Yapilan bir sistematik incelemeye göre, masaj terapisi özellikle ameliyatla ilişkili ağrılar olmak üzere kanser ağrısını önemli ölçüde azaltmaktadır. Çeşitli masaj türleri arasında ayak refleksolojisi vücut ya da aroma masajından daha etkili olabilir (32).

\section{Desensitizasyon Eğitimi}

Desensitizasyon eğitimi, ağr1 yoğunluğunu azaltmak için benign afferent duyusal uyaranların kullanıldığı çeşitli rehabilitasyon tekniklerini içerir. Periferik desensitizasyon teknikleri, özellikle kemoterapi kaynaklı hiperaljezi ve allodini gibi periferik nöropatiler ve karmaşı bölgesel ağr1 sendromları olan hastalar için kullanılabilmektedir $(35,36)$. Hafif dokunmaya karş1 aşırı duyarlılı̆̆1 olan alanlar, yoğunluğu tolerasyon ölçütünde artırılacak şekilde derin basınçla duyarsızlaştırılabilir (36).

\section{Manuel Terapi}

Manuel terapi bugüne kadar muhtemelen hastanın tolere edebilirliği ve güvenliğiyle ilgili kaygılardan dolayı pek tercih edilmemiştir, ancak akut yanıklı hastalara hipertrofik kontraktürü önlemek için manuel tedavi verildiği göz önüne alındığında, kanserde uygun şekilde uygulanırsa bu teknikler ağrıyı, kontraktil yapıların gerginliğini, inflamasyonu ve hipoksiyi azaltma potansiyeline sahiptir. Yapılan bir çalışmada manuel terapinin; ağrıyı kısa süreli, fibrozis sonuçlarını ise uzun süreli azalttığı ancak lenf ödem, deri dökülmeleri ve eritem durumunda uygulanmaması gerektiği belirtilmiştir (37).

Sinir mobilizasyonu (SM) manuel terapinin bir parçasıdır. SM, nörojenik ağrıda hiperaljeziyi kalıcı bir etki ile azaltır, motor gücün daha çabuk iyileşmesini hızlandırır, nörotrofik faktörlerin salınmasını sağlayarak iskelet kasını elektrik stimülasyonuna veya aktif egzersize benzer şekilde uyarır, sinir rejenerasyonunu hızlandırır ve vasküleriteyi de artırır. SM teknikleri, inflamatuvar atıkların uzaklaştırılması ve fibroblastik aktivitenin sınırlanmasında rol oynayarak hipoaljezik etkiler meydana getirir (38).

\section{Ortezler}

Kanser hastalarında ağrıyı önlemek amaciyla kullanılan ortezler genellikle boyun, gövde ve sırtı stabilize etmeye yöneliktir. Bununla birlikte, ayak-ayak bileği ortezleri ve el ve el bileği splintleri distal ekstremite ağrıs1 olan hastalar için faydalı olabilir (39). Deri bütünlüğü kanser hastalarında muhakkak göz önünde bulundurulmalıdır. Beslenme problemlerine bağlı olarak subkutan yağ dokusunun azalması nedeniyle cildin basinca karşı tolerasyonu azalır. Bu sebeple hastalara ortez uygulamasi sirasinda ve sonrasinda dikkatli olunmalıdır. Ayrıca kullanılan steroidal ilaçlar nedeniyle deri kolayca yaralanabilir, dökülür ve sonuçta ortez altında vücudun 1sıy1 yayma yeteneği azalır. İrrite olmuş deri alanında subkutan yapıların normal kaymasını engelleyen fibrotik değişiklikler oluşur. $\mathrm{Bu}$ alanların iyileşmesi geç olmaktadır ve enfeksiyon görülme ihtimali yüksektir (40).

\section{Pozisyonlama}

Yastıklar, destekler, hastane yastıkları ve adaptif ekipmanların stratejik kullanımı ağrısız eklem hareketini ve hastaları destekleyebilmeyi sağlamaktadır. Ancak bu etkili yaklaşımlar yeterince dikkat çekmemektedir. Şiddetli zayıflık ve motor defisiti olan hastaların dinlenme pozisyonunda stabilize edilmesi sadece ağrıyı azaltmakla kalmaz, aynı zamanda savunmasız kemikli çıkıntılı vücut bölgelerini de korur (35).

\section{Terapötik Egzersiz}

Genellikle diğer modalitelerle birlikte spesifik amaçlara yönelik tasarlanan terapötik egzersizler en etkili tedavi olabilirler. Birçok değişik egzersiz yaklaşımının genel amacı; ağrıyı azaltmak, zayıf kasları güçlendirmek, vertebradaki mekanik yükü azaltmak, genel sağlığı geliştirmek, hipermobil segmentleri stabilize etmek, duruşu düzeltmek ve hareketi artırmaktır. Aktif ve pasif egzersizler; dolaşımın hızlanması, kontraktil yapıların gerginliğinin azalması ve kontraktür oluşumunun önlenmesi ile ağrının hafifletilmesine yardımc1 olur.

Kuvvetlendirme ve germe egzersizlerinin ağrıların azalmasında rol aldığını gösteren çalışmalar bulunmaktadır (34). Ağrılı bir vücut bölümündeki kasların kuvvetini ve dayanıklılığını arttırmayı amaçlayan terapötik egzersizler ağrının azaltılmasında önemli rol oynarlar (35). Omurgada instabiliteden kaynaklanan ağrıların giderilmesinde özellikle multifidus kaslarının omurgaya dinamik stabilizasyon sağlaması gerekmektedir.

Yürüme, bisiklet ve yüzme ya da su içi egzersizler gibi aerobik karakterdeki egzersizlerin, ağrı eşiğini yükselttiği ve ağr1 
algılamasını azalttığ 1 bildirilmektedir. Eğer düzenli şekilde orta şiddette aerobik egzersiz yapılırsa endojen opioidlerin üretimi artar ve sonuçta ağrı azalır (34). Su içi egzersizler sert eklemlerde hareketle oluşan ağrının hafifletilmesinde yararlı olabilir. Ayrica su hareketleri masaj etkisi oluşturarak kasların gevşemesini ve anksiyetenin azalmasını sağlar (40). Yapılan bir sistematik incelemenin sonuçlarına göre, aerobik, dirençli ve alternatif egzersiz türlerinin (örn. Yoga) birleşiminden oluşan tedaviler hastalar için güvenli ve iyi tolere edilebilirdir. Kanser hastalarının fizyolojik ve hasta tarafindan bildirilen sonuçlarında anlamlı gelişmeler sağlar (41).

\section{Psikolojik ve Davranışsal Yaklaşımlar}

İleri dönem kanser hastalarında ağrı deneyimi karmaşık bir yapı halini almıştır. Psikolojik faktörler hem ağrı deneyimini hem de tedaviye yanitı etkilemektedir. Terminal dönem kanser hastalarında ağrıya kesin bir çözüm yolunun bulunması konusundaki kisitllikklar, psikolojik faktörlerin ve müdahalelerin ağrı deneyimi üzerindeki etkisine olan ilgiyi artırmıştır (42). Zaza ve ark. anksiyete, depresyon, duygusal sikınt1, korku ve endişe ile kanser ağrısı arasındaki ilişkiyi bir sistematik incelemede ele almışlar ve yüksek düzeyde psikolojik sıkıntının daha şiddetli ağrı ile ilişkili olduğuna dair güçlü kanttlar elde etmişlerdir (43).

Ağrı ile karşı karşıya kalan çoğu hasta bununla başa çıkmak için yollar geliştirir. Terminal dönem kanser hastalarında ağrıyla baş etmek için; dikkat dağıtma, hayal kurma, gevşeme, aktivite kalıplarının değiştirilmesi ve dua gibi stratejiler vardır. $\mathrm{Bu}$ stratejilerin herhangi birinin ağrı şiddeti ile ilişkisinin sürekli olduğuna dair çok az kanıt vardır. Bununla birlikte, ilerlemiş kanseri olan hastalarda ağniyla başa çıkabilme yeteneğine olan inançla ağrı arasında ilişkinin olduğuna dair kanıtlarda vardır. Örneğin, katastrofisi olan hastalar daha fazla ağrı bildirirken, öz-yeterliği ve ağriyı kontrol etme yeteneği yüksek ve çaresizlik algısı düşük olan hastalar daha az ağr1 bildirmektedirler.

Palyatif bakıma ihtiyacı olan hastalarda bu konu üzerine yapılmış az sayıda çalışma bulunmaktadır. Kognitif davranışsal terapinin bileşenleri, gevşeme ve hayal kurmayı içeren eğitim odaklı yaklaşım, terminal dönem kanser hastalarında ağrıyı yönetme becerilerini öğretmek için etkin bir şekilde kullanılmaktadır (42). Yapılan bir meta-analiz bu tür becerilere dayalı müdahalelerin ağrı şiddetinde iyileşmeler sağladığını belirtmektedir (44).

\section{SONUÇ}

Palyatif bakım alan kanserli hastalarda ağrının kontrolü ile yaşam kalitesinin artırılması ve hasta yakılarının desteklenmesi gerekmektedir. Bu sebeple, ülkemizde palyatif bakım hizmetlerinin sağlık sistemi ile bütünleşebilmesi önemlidir. Kanser hastalarında ağrı tedavisi için öncelikli yaklaşım iyi değerlendirme ve farmakolojik ajanlardır ancak, fizyoterapi ve rehabilitasyonun birkaç uygulamanın çok ötesine geçen sağlık hizmeti olduğunun ve ağrı tedavisi ve bakım kalitesini arttırdığının da bilinmesi gerekmektedir. Palyatif bakımda sağlık hizmetleri maliyetlerini düşürmek, aynı zamanda hasta sonuçlarını ve bakım memnuniyetini artırmak için rehabilitasyon hizmetlerinin onkoloji bakımına daha iyi entegrasyonu gerekmektedir.

\section{REFERANSLAR}

1. Gökçınar D, Kahveci K. Dünyada ve Türkiye'de palyatif bakım. In: Palyatif Bakım, Gökçınar D, Kahveci K (Eds), Nobel Tıp Kitabevleri Tic. Ltd. Şti; 2014:1-5.

2. WHO Definition of Palliative Care. http://www.who.int/ncds/management/palliativecare/en/.

3. Ovayolu Ö, Ovayolu N. Palyatif Bakım Alan Kanser Hastalarının Ağrı Yönetiminde İntegratif Yaklaşımlar. Hacettepe Üniversitesi Hemşirelik Fakültesi Dergisi. 2017; 4(3):54-64.

4. Reis-Pina P, Lawlor PG, Barbosa A. Cancer-Related Pain Management and the Optimal Use of Opioids. Acta Med Port. 2015;28(3):376-81

5. Keenan A, Keithley JK. Integrative Review: Effects of Music on Cancer Pain in Adults. Oncol Nurs Forum. 2015;42(6):368-75.

6. Ripamonti C, Dickerson ED. Strategies for the treatment of cancer pain in the new millennium. Drugs. 2001;61:955-77.

7. Myers J, Shetty N. Going beyond efficacy: Strategies for cancer pain management. Curr Oncol. 2008;15(1):41-9.

8. van den Beuken-van Everdingen MH, de Rijke JM, Kessels AG, Schouten HC, van Kleef M, Patijn J. High prevalence of pain in patients with cancer in a large population-based study in The Netherlands. Pain 2007;132:312-320.

9. Kumar SP. Cancer Pain: A Critical Review of Mechanism-based Classification and Physical Therapy Management in Palliative Care. Indian J Palliat Care. 2011;17(2): 116-126.

10. Şenel G, Oğuz G, Koçak N, Karaca Ş, Kaya M, Kadığulları N. Palyatif bakım kliniğinde yatan 
kanser hastalarında ağrı tedavisi ve opioid kullanımı. Ağr1. 2016;28(4):171-176

11. Schmidt BL, Hamamoto DT, Simone DA, Wilcox GL. Mechanism of cancer pain. Mol Interv. 2010;10(3):164-178.

12. Smith TJ, Saiki CB. Cancer Pain Management. Mayo Clin Proc. 2015;90(10):1428-39

13. Dalal S, Bruera E. Assessment and management of pain in the terminally ill. Prim Care. 2011;38(2):195223.

14. Saunders $C$. The management of terminal malignant disease. 1st edition. London: Edward Arnold; 1978.

15. Dalal S, Bruera E. Assessing Cancer Pain. Curr Pain Headache Rep. 2012;16:314-324

16. Wagner-Johnston ND, Carson KA, Grossman SA. High outpatient pain intensity scores predict impending hospital admissions in patients with cancer. J Pain Symptom Manage. 2010;39(2):180-5.

17. Fishman B, Pasternak S, Wallenstein SL, Houde RW, Holland JC, Foley KM. The memorial pain assessment card. A valid instrument for the evaluation of cancer pain. Cancer. 1987;60(5):11518.

18. Lawlor PG, Gagnon B, Mancini IL, et al. Occurrence, causes, and outcome of delirium in patients with advanced cancer: a prospective study. Arch Intern Med. 2000;160(6):786-94.

19. Minagawa H, Uchitomi $Y$, Yamawaki S, Ishitani K. Psychiatric morbidity in terminally ill cancer patients. A prospective study. Cancer 1996;78(5):1131-7.

20. Breitbart W, Rosenfeld B, Roth A, Smith MJ, Cohen K, Passik S. The Memorial Delirium Assessment Scale. J Pain Symptom Manage 1997;13(3):128-37.

21. Herr K, Bjoro K, Decker S. Tools for assessment of pain in nonverbal older adults with dementia: a state-of-the-science review. J Pain Symptom Manage 2006;31(2):170-92.

22. Raphael J, Hester J, Ahmedzai $S$ et all. Cancer pain: part 2: physical, interventional and complimentary therapies; management in the community; acute, treatment-related and complex cancer pain: a perspective from the British Pain Society endorsed by the UK Association of Palliative Medicine and the Royal College of General Practitioners. Pain Med. 2010;11(6):872-96.

23. Guru K, Manoor UK, Supe SS. A comprehensive review of head and neck cancer rehabilitation: physical therapy perspectives. Indian $\mathrm{J}$ Palliat Care. 2012;18(2):87-97

24. Chou R, Huffman LH: Nonpharmacologic therapies for acute and chronic low back pain: A review of the evidence for an American Pain Society/American College of Physicians clinical practice guideline. Ann Intern Med. 2007;147(7):492-504.

25. Denys EH: AAEM minimonograph \#14: The influence of temperature in clinical neurophysiology. Muscle Nerve. 1991;14(9):795-811.

26. Cameron MH. Physical Agents in Rehabilitation: From Research To Practice. Second Edition. Philadelphia: W.B. Saunders; 2003:137-141.

27. Almeida MO, Silva BN, Andriolo RB, Atallah AN, Peccin MS. Conservative interventions for treating exerciserelated musculotendinous, ligamentous and osseous groin pain. Cochrane Database Syst Rev 2013; 6(6):CD009565.

28. Loh J, Gulati A. The use of transcutaneous electrical nerve stimulation (TENS) in a major cancer center for the treatment of severe cancer-related pain and associated disability. Pain Med. 2015;16(6):1204-10.

29. Clarkson JE, Worthington HV, Furness S, McCabe M, Khalid T, Meyer S. Interventions for treating oral mucositis for patients with cancer receiving treatment. Cochrane Database Syst Rev. 2010;4(8):CD001973

30. Smoot B, Chiavola-Larson L, Lee J, Manibusan $\mathrm{H}$, Allen DD. Effect of low-level laser therapy on pain and swelling in women with breast cancerrelated lymphedema: a systematic review and meta-analysis. $\mathrm{J}$ Cancer Surviv. 2015;9(2):287-304

31. Chernack B, Knowlton SE, Kohler MJ. The Use of Ultrasound in Palliative Care and Hospice. Am J Hosp Palliat Care. 2017;34(4):385-91

32. Lee SH, Kim JY, Yeo S, Kim SH, Lim S. MetaAnalysis of Massage Therapy on Cancer Pain. Integr Cancer Ther. 2015;14(4):297-304.

33. Boyd C, Crawford C, Paat CF, Price A, Xenakis L, Zhang W. The Impact of Massage Therapy on Function in Pain Populations-A Systematic Review and Meta-Analysis of Randomized Controlled Trials: Part II, Cancer Pain Populations. Pain Med. 2016;17(8):1553-1568

34. Karaduman AA, Tunca Yilmaz Ö. Fizyoterapi ve Rehabilitasyon. (Cilt 1) Genel Fizyoterapi. Hipokrat Kitabevi \& Pelikan Kitabevi, Ankara; 2016:120-123.

35. Cheville AL, Basford JR. Role of Rehabilitation Medicine and Physical Agents in the Treatment of Cancer-Associated Pain. J Clin Oncol. 2014;32(16):1691-1702.

36. Kumar SP, Saha S. Mechanism-based Classification of Pain for Physical Therapy Management in Palliative care: A Clinical Commentary. Indian J Palliat Care. 2011;17(1):80-6.

37. Krisciunas GP, Golan H, Marinko LN, Pearson W, Jalisi S, Langmore SE. A novel manual therapy programme during radiation therapy for head and neck cancer -our clinical experience with five patients. Clin Otolaryngol. 2016;41(4):425-31

38. Casanova-García C, Lerma Lara S, Pérez Ruiz M, Ruano Domínguez D, Santana Sosa E. Nonpharmacological treatment for neuropathic pain in children with cancer. Med Hypotheses. 2015;85(6):791-7

39. Utter A, Anderson ML, Cunniff JG, et al. Video fluoroscopic analysis of the effects of three commonly-prescribed off-the-shelf orthoses on vertebral motion. Spine. 2010; 35(12):525-529.

40. Bruera ED, Portenoy RK. Cancer Pain: Assessment and Management.2nd Edition, Cambridge University Press, 2010,364-366.

41. Fairman CM, Focht BC, Lucas AR, Lustberg MB. Effects of exercise interventions during different treatments in breast cancer. J Community Support Oncol. 2016;14(5):200-9

42. Syrjala KL, Jensen MP, Mendoza ME, Yi JC, Fisher HM, Keefe FJ. Psychological and Behavioral Approaches to Cancer Pain Management. J Clin Oncol. 2014;32:1703-1711 
43. Zaza C, Baine N. Cancer pain and psychosocial factors: A critical review of the literature. J Pain Symptom Manage. 2002;24(5):526-42.
44. Sheinfeld Gorin S, Krebs P, Badr H, et al. Metaanalysis of psychosocial interventions to reduce pain in patients with cancer. J Clin Oncol. 2012;30(5):539-47 